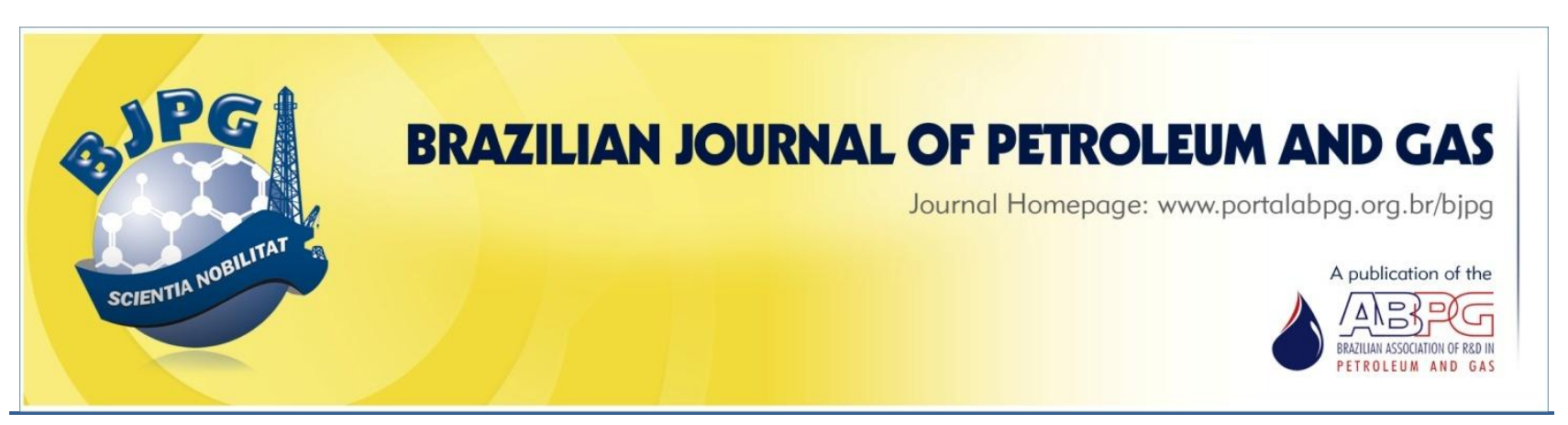

\title{
SYNTHESIS OF HMF FROM GLUCOSE IN AQUEOUS MEDIUM USING NIOBIUM AND TITANIUM OXIDES
}

\author{
${ }^{\text {a }}$ Siqueira, B. G.; ${ }^{\text {a }}$ Silva, M. A. P.; ${ }^{\text {a }}$ Moraes, ${ }^{1}{ }^{1}$ \\ ${ }^{a}$ Escola de Química, Universidade Federal do Rio de Janeiro, RJ, Brazil
}

\section{ABSTRACT}

The effects of $\mathrm{H}_{3} \mathrm{PO}_{4}$ treatment on the catalytic activity of both niobium and titanium oxides were evaluated during the synthesis of 5-hydroxymethylfurfural (HMF) from glucose in aqueous medium. Catalysts performances were related to acidic and basic properties of oxides. The presence of weak basic sites favored fructose formation via glucose isomerization. The increase in acid strength favored, initially, the formation of 5-hydroxymethylfurfural and, later, its transformation into organic acids and humins. Among the catalysts used in the experiments, phosphated $\mathrm{TiO}_{2}$ showed the best results, although all catalysts exhibited a significant deactivation along the reaction time.

\section{KEYWORDS}

HMF; glucose; oxides; aqueous medium

\footnotetext{
${ }^{1}$ To whom all correspondence should be addressed.

Address: Escola de Química, Universidade Federal do Rio de Janeiro, Av. Athos da Silveira Ramos,149, BI. E, Ilha do Fundão, Rio de Janeiro - RJ, Brazil, Zip code 21941-909

Telephone: +55 21 8549-0484| E-mail: caetano@eq.ufrj.br

doi:10.5419/bjpg2013-0006
} 


\section{INTRODUCTION}

In past decades, especially in recent years, the interest in petrochemicals and fuels production from biomass has grown substantially. An increase in the societal demand for more sustainable and environmentally responsible products led to the intensification of these activities.

In this context, numerous building blocks are being studied by the scientific community. The 5hydroxymethylfurfural (HMF) appears among the most promising ones. This compound can be used as a renewable intermediate for the production of different biofuels and monomers in the petrochemical industry as levulinic acid and 2,5 furan dicarboxylic acid (2,5 FDCA) (Lanzafame et al., 2011; Petersen and Werpy , 2004).

Several biofuels like gasoline, diesel, and kerosene, can be synthesized by the 2,5 FDCA esterification or by the HMF etherification with different chain-size alcohols and olefins (Gruter, 2010A; Gruter, 2010B; Gruter and Manzer, 2010A; Gruter and Manzer, 2010B). This process leads to the formation of different furan derivatives with specific and customizable fuel properties such as initial and final boiling point, solidification point, heat value, vapor pressure, along with others.

The HMF can be obtained by hexoses dehydration, especially the fructose (Lewkowski, 2001), as illustrated in Figure 1. Ketohexoses, as fructose, are much more reactive than aldohexoses, as glucose. Thus, ketohexoses get dehydrated by HMF faster than aldohexoses, reducing the formation of side products as organic acids and a tarry oligomeric material called humins. Although the use of glucose as feedstock for HMF production presents some technical difficulties, its low cost, when compared to the use of fructose, makes it utilization competitive (Corma et al., 2007).

Therefore, rising scientific efforts are in place to find novel ways of producing HMF with good yields and in a feasible way. Currently, processes using biphasic systems for continuous extraction of the produced HMF and ionic liquids aiming the reduction of HMF side-products are being developed (Leshkov et al., 2006; Lansalot-Matras and Moreau, 2003; Tong et al., 2010). Meanwhile, financial issues associated with the process of solvent separation and the cost of ionic liquids still represent a challenge.

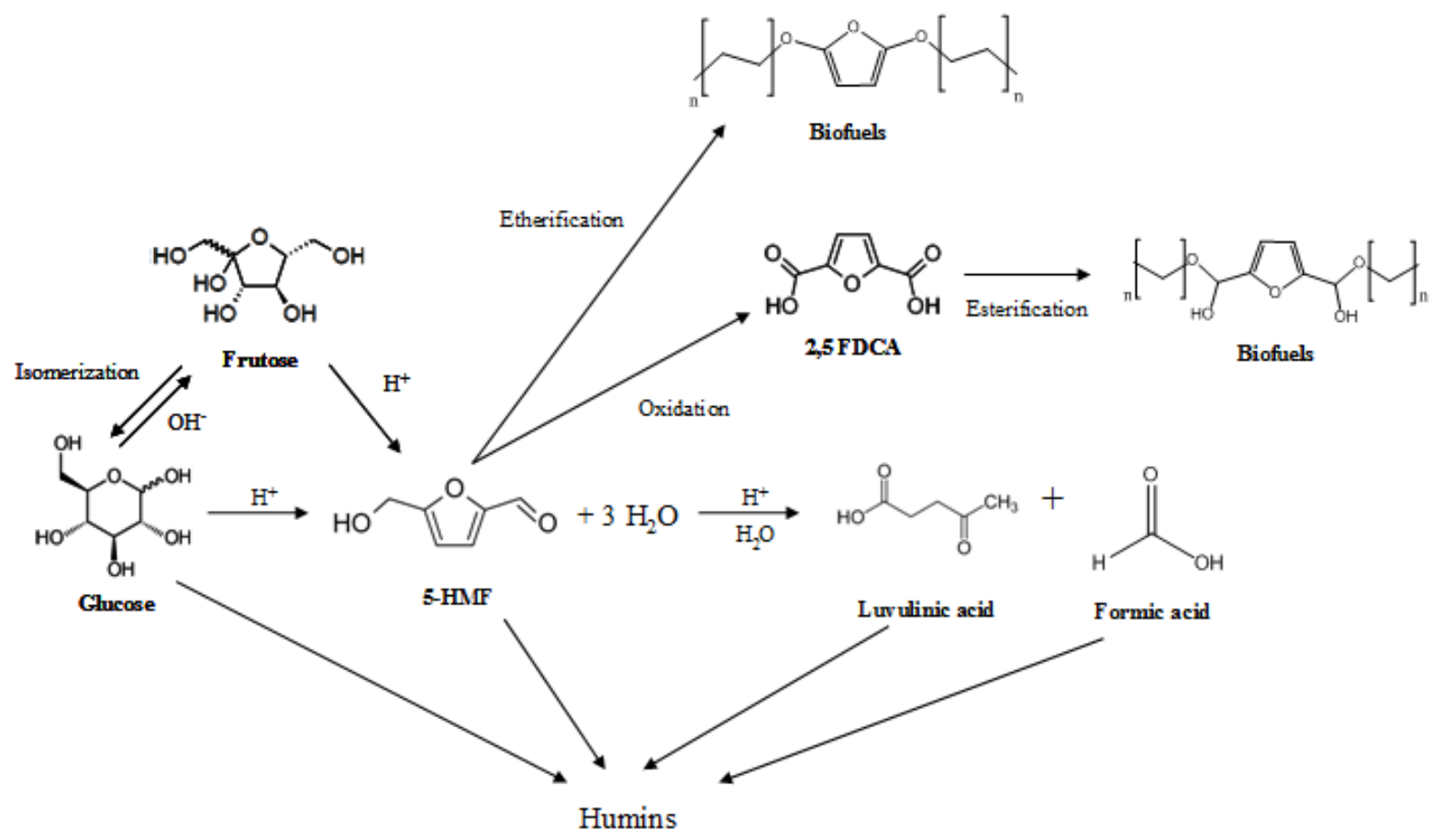

Figure 1. A typical reaction scheme for HMF production from hexoses. 
In this scenario, the aqueous medium displays interesting advantages such as low cost and the inexistence of media toxicity. It also shows high sugar solubility. However, higher HMF yields must be achieved in order to make this process competitive.

The use of homogeneous acid catalysts in aqueous medium was the first attempt studied involving the dehydration of hexoses to produce HMF. Actually, hundreds of different organic and inorganic acids are qualified to dehydrate hexoses (Fan et al., 2011). Nevertheless, problems related to their toxicity, difficulty in separation, and corrosiveness lead to, from a process standpoint, an increased interest broadening in the use of heterogeneous catalysts as zeolites, heteropoly acids, resins, oxides, and others.

Oxides and phosphates are solid acids also used in a large number of reactions such as hydration, esterification, etherifications, dehydrations, and other processes which require a strong acid strength. Niobium acid (hydrated niobium oxide $\mathrm{Nb}_{2} \mathrm{O}_{5} \cdot \mathrm{nH}_{2} \mathrm{O}$ ) is known to be a very water tolerant acid catalyst (Okuhara , 2002) and, thus, a very promising catalyst for the dehydration of hexones to HMF. This catalyst was evaluated in the dehydration of fructose in a continuous flow reactor, and the results suggested that HMF decomposition products were not formed under the employed conditions (Cartini et al., 2011).

Niobium phosphate was also evaluated in the dehydration of fructose in water using in a fixed bed reactor (Cartini et al., 2006). In this work, a higher intrinsic effective acidity, in terms of number of acid sites, for the niobium phosphate catalyst was related to a higher initial activity and also to a higher deactivation during the experiments, when compared to the niobium oxide catalyst. Selectivity of around $35 \% \mathrm{~mol} / \mathrm{mol}$ was achieved with fructose conversion of $65 \% \mathrm{~mol} / \mathrm{mol}$.

The role of Brönsted and Lewis acid sites in $\mathrm{Nb}_{2} \mathrm{O}_{5}$ and phosphated $\mathrm{Nb}_{2} \mathrm{O}_{5}$ was investigated in the transformation of glucose into HMF (Nakajima et al., 2011). In this work, the authors found that Brönsted acid sites have great ability to hydrate formed HMF in water, reducing the HMF yield. In contrast, Lewis acid sites are able to selectively dehydrate glucose to HMF and also to promote the isomerization of glucose into fructose. Indeed, glucose-fructose isomerization may proceed either via hydride transfer (Lewis acid catalyzed reaction) or by proton transfer (basic catalyzed reaction), which is well known in the literature (Souza et al., 2012).

Some metal oxides, for instance $\mathrm{TiO}_{2}$ and $\mathrm{ZrO}_{2}$, act as acid and base catalysts for hexoses dehydration in hot-compressed water (Watanabe et al., 2005A). The basic sites are responsible for isomerizing a less reactive feedstock, such as glucose into fructose via proton transfer, while the acid sites catalyze hexoses dehydration into HMF. The ability to isomerize glucose into fructose allows a significant increment in the HMF yield.

TPD measurements were used to evaluate the acidic and basic catalytic properties of $\mathrm{TiO}_{2}$ (anatase and rutile) and $\mathrm{ZrO}_{2}$ (monoclinic/tetragonal mixture) on glucose and fructose dehydration in hot compressed water (Watanabe et al., 2005B). Among the three catalysts, $\mathrm{TiO}_{2}$ anatase showed the highest density of acidic and basic sites while $\mathrm{ZrO}_{2}$ showed the highest amount of acidic and basic sites. $\mathrm{TiO}_{2}$ rutile did not show any catalytic activity for glucose dehydration.

In these experiments, $\mathrm{TiO}_{2}$ anatase showed the highest $\mathrm{HMF}$ yield while $\mathrm{ZrO}_{2}$ showed the highest fructose yield. These results suggest that the density of acid and base sites was probably important for glucose dehydration to HMF, while the amount of weak to moderate basic sites was required for glucose isomerization into fructose.

As mentioned by various researchers (Okazaki et al., 1987; Tang et al.; 2010; Yang et al., 2011), metal oxides treated with $\mathrm{H}_{3} \mathrm{PO}_{4}$ have a higher density of acid sites and display an enhanced acid strength, which are important in several acid catalyzed reactions.

However, the effect of $\mathrm{TiO}_{2}$ anatase treated with phosphoric acid on glucose dehydration in hot compressed water aiming the formation of $\mathrm{HMF}$ has never been reported in the literature. Thus, the role of the treatment of titanium oxide and niobic acid with phosphoric acid was evaluated on glucose dehydration to HMF in aqueous medium. The catalytic performance was related to the acidic and basic properties through the temperatureprogrammed $\mathrm{CO}_{2}$ desorption ( $\mathrm{CO}_{2}$-TPD) and Fourier transform infrared spectroscopy pyridine desorption (pyridine- FTIR). 


\section{EXPERIMENTAL}

\subsection{Materials}

Glucose (99 wt.\%) and HMF (99 wt.\%) were purchased from Sigma-Aldrich and Satochem, respectively. $\mathrm{Nb}_{2} \mathrm{O}_{5} \cdot \mathrm{nH}_{2} \mathrm{O}$ (99.5 wt.\%) was supplied by Companhia Brasileira de Metalurgia e Mineração (CBMM) in powder form (> 99.5 wt.\%). $\mathrm{TiO}_{2}$ anatase (99 wt.\%) was purchased from SigmaAldrich.

\subsection{Catalysts preparation}

The phosphated niobium $\left(\mathrm{Nb}_{2} \mathrm{O}_{5}-\mathrm{P}\right)$ was prepared according to the method described elsewhere (Yang et al., 2011) by mixing $10 \mathrm{~g}$ of $\mathrm{Nb}_{2} \mathrm{O}_{5} \cdot \mathrm{nH}_{2} \mathrm{O}$ in $135 \mathrm{~mL}$ of $1 \mathrm{M} \mathrm{H}_{3} \mathrm{PO}_{4}$. The suspension was stirred for 52 hours at room temperature. The suspension was aged for 8 hours and, then, filtered. Following, the precipitate was washed several times with deionized water until reaching a neutral $\mathrm{pH}$. After filtration, the powder was dried in vacuum at $60^{\circ} \mathrm{C}$ for 18 hours and, then, calcinated in air at $300^{\circ} \mathrm{C}$ with slow heating $\left(5^{\circ} \mathrm{C} \cdot \mathrm{min}^{-1}\right)$ for 3 hours.

The phosphated titanium catalyst $\left(\mathrm{TiO}_{2}-\mathrm{P}\right)$ was prepared using the same procedure. Pure niobic oxide $\left(\mathrm{Nb}_{2} \mathrm{O}_{5}\right)$ and anatase titanium oxide $\left(\mathrm{TiO}_{2}\right)$ were dried and calcinated under the same conditions.

\subsection{Catalysts characterization}

Samples surface-areas analyses were measured by nitrogen adsorption at $-196^{\circ} \mathrm{C}$ using a sorptometer (ASAP-2020, Micromeritics). The samples were degassed at $300^{\circ} \mathrm{C}$ for $18 \mathrm{~h}$ prior to measurements. Surface areas were determined by BET method.

X-ray diffraction analyses (XRD) were carried out in a Rigaku Miniflex difratometer equipped with a copper tube $(\lambda=1.5417 \AA)$, operating at $30 \mathrm{kV}$ and $15 \mathrm{~mA}$ and with acquisition intervals of $2 \theta=0.050$, and 2 second per pass.

The basic properties were studied by temperature-programmed desorption of $\mathrm{CO}_{2}$. $\mathrm{CO}_{2}$ TPD analyses were carried out in a Balzers Omnistar QMS200 quadrupole mass spectrometer. The samples $(\sim 500 \mathrm{mg})$ were pre-treated in situ under He flow $\left(50 \mathrm{~mL} \cdot \mathrm{min}^{-1}\right)$ at $400^{\circ} \mathrm{C}$ for $30 \mathrm{~min}$.
After cooling to room temperature, under He flow, $\mathrm{CO}_{2}$ was adsorbed for 1 hour at room temperature and with $12.5 \mathrm{~mL}$. $\mathrm{min}^{-1}$ flow. Then, the bulk $\mathrm{CO}_{2}$ was purged with $\mathrm{He}$ for 1 hour at room temperature. The desorption was performed under He flow $\left(50 \mathrm{~mL} \cdot \mathrm{min}^{-1}\right)$ until $800^{\circ} \mathrm{C}\left(10^{\circ} \mathrm{C} \cdot \mathrm{min}^{-1}\right)$.

Pyridine-FTIR analyses were performed in a Nicolet Magna 560 spectrophotometer (4000 $400 \mathrm{~cm}^{-1}$ with $4 \mathrm{~cm}^{-1}$ resolution). The samples ( $30 \mathrm{mg})$ treatments were performed under high vacuum at $400^{\circ} \mathrm{C}$ for 1 hour, followed by 5 pulses of air at $400^{\circ} \mathrm{C}$. Then, the samples were subjected to high vacuum for $30 \mathrm{~min}$. Later, pyridine was adsorbed for $30 \mathrm{~min}$ at $25^{\circ} \mathrm{C}$ and $0.266 \mathrm{kPa}$, followed by desorptions under high vacuum at $25^{\circ} \mathrm{C}$ for $30 \mathrm{~min}, 150^{\circ} \mathrm{C}$ for $30 \mathrm{~min}, 250^{\circ} \mathrm{C}$ for $30 \mathrm{~min}$ and $350^{\circ} \mathrm{C}$ for $30 \mathrm{~min}$.

After pyridine desorption in each temperature, the samples were kept under vacuum and room temperature for $30 \mathrm{~min}$ before spectrum acquisitions. These spectra were obtained with $4 \mathrm{~cm}^{-1}$ resolution after 120 readings at room temperature. Acid-site densities were calculated using $1450 \mathrm{~cm}^{-1}$ and $1550 \mathrm{~cm}^{-1}$ bands for Lewis and Brönsted acid sites, respectively. Absorptivity coefficients for each band were obtained from available literature (Emeis, 1993).

\subsection{Reaction procedure}

All the catalytic tests were carried out in a $300 \mathrm{~mL}$ stainless steel reactor with mechanical agitation and controlled temperature. Prior to reaction, milliQ water was treated in an ultrasound bath for 20 minutes, at room temperature, to remove dissolved oxygen. Then, $2 \mathrm{~g}$ of $\mathrm{d}$-glucose were dissolved in 198g of degassed water and the catalyst was added in a catalyst/glucose mass ratio of 0.10 . Subsequently, a small flow of ultrapure nitrogen was passed through the mixture for 30 minutes to ensure the complete removal of oxygen. Then, the reactor was purged three times with nitrogen, pressurized to $1723.7 \mathrm{kPa}$ with the same gas and, later, heated to the reaction temperature. Zero time was considered when temperature reached $200^{\circ} \mathrm{C}$. At this time, agitation at 700rpm was turned on. Reaction progress was monitored by taking samples of reaction medium.

\subsection{Product analysis}

Products and reactants were analyzed by HPLC 
Agilent 1260 with diode array detector (DAD) and evaporative light scattering detector (ELSD) in duplicates. Glucose consumption was determined with a Zorbax Cabohydrate column $(4.6 \times 250 \mathrm{~mm} 5$ microns), water (25)/acetonitrile(75) as mobile phase, $1.4 \mathrm{~mL} / \mathrm{min}$ flow, and an ELSD detector. The HMF production was determined with Zorbax Eclipse plus C18 (4.6 x 100mm 3.5 microns), water (10)/acetonitrile(75)/methanol(15) as mobile phase, $0.7 \mathrm{~mL} \cdot \mathrm{min}^{-1}$ flow and DAD detector.

In the experiments, glucose conversion $\left(X_{G}\right)$, $\mathrm{HMF}$ yield $\left(\mathrm{Y}_{\mathrm{HMF}}\right)$, selectivity to $\mathrm{HMF}\left(\mathrm{S}_{\mathrm{HMF}}\right)$, and selectivity to fructose $\left(Y_{F}\right)$ are defined as follows:

$$
\begin{aligned}
& X_{G}=\frac{n G_{0}-n G}{n G_{0}} \\
& Y_{H M F}=\frac{n H M F}{n G_{0}} \\
& S_{H M F}=\frac{Y_{H M F}}{X_{G}} \\
& Y_{F}=\frac{n F}{n G_{0}}
\end{aligned}
$$

Where $n G_{0}$ is the number of moles of glucose initially fed in the reactor; $n G, n H M F$ and $n F$ are the number of moles of glucose, and $H M F$ and fructose, respectively, are presented in a given reaction time.

Although levulinic and formic acids could be identified in the chromatograms, their signals and resolutions were very poor, precluding the determination of their yields.

\section{RESULTS AND DISCUSSIONS}

\subsection{Surface areas}

The catalysts surface areas are shown in Table 1. Surface areas of $\mathrm{TiO}_{2}$ and $\mathrm{TiO}_{2}-\mathrm{P}$ were similar

Table 1. Surface areas.

\begin{tabular}{cc}
\hline Catalyst & BET area $\left(\mathrm{m}^{2} / \mathrm{g}\right)$ \\
\hline $\mathrm{TiO}_{2}$ & 8.0 \\
$\mathrm{TiO}_{2}-\mathrm{P}$ & 8.5 \\
$\mathrm{Nb}_{2} \mathrm{O}_{5}$ & 83 \\
$\mathrm{Nb}_{2} \mathrm{O}_{5}-\mathrm{P}$ & 73 \\
\hline
\end{tabular}

indicating that treatment with $\mathrm{H}_{3} \mathrm{PO}_{4}$ did not modify this property for titanium catalysts. However, $\mathrm{Nb}_{2} \mathrm{O}_{5}-\mathrm{P}$ presented a reduction on its surface area when compared to $\mathrm{Nb}_{2} \mathrm{O}_{5}$, phenomenon in accordance with the literature (Okazaki et al. 1987; Tang et al., 2010). The phosphoric acid treatment results in the formation of amorphous niobium phosphate on the $\mathrm{Nb}_{2} \mathrm{O}_{5}$ (Tang et al., 2010), which could be responsible for plugging pores and, consequently, reducing surface area.

\subsection{X-Ray Diffraction}

The catalysts X-ray diffractograms are shown in Figure 2. As one can be observe in Figure 2, the $\mathrm{Nb}_{2} \mathrm{O}_{5}$ and $\mathrm{Nb}_{2} \mathrm{O}_{5}-\mathrm{P}$ that calcinated at $300^{\circ} \mathrm{C}$ were amorphous materials, as reported in the literature (Armaroli et al., 2000; Tang et al., 2010).

Regarding the $\mathrm{TiO}_{2}$ diffractogram, peaks at $25.5^{\circ}$ associated to the anatase phase (JCPDS, No. 211272) were observed, while no peaks, at $27.45^{\circ}$, were associated with rutile phase for this catalyst.

Concerning the $\mathrm{TiO}_{2}-\mathrm{P}$ catalyst, no evidence peaks of titanium phosphate, at $27.5^{\circ}$, appeared in the $x$-ray diffraction (Fan et al., 2008). In

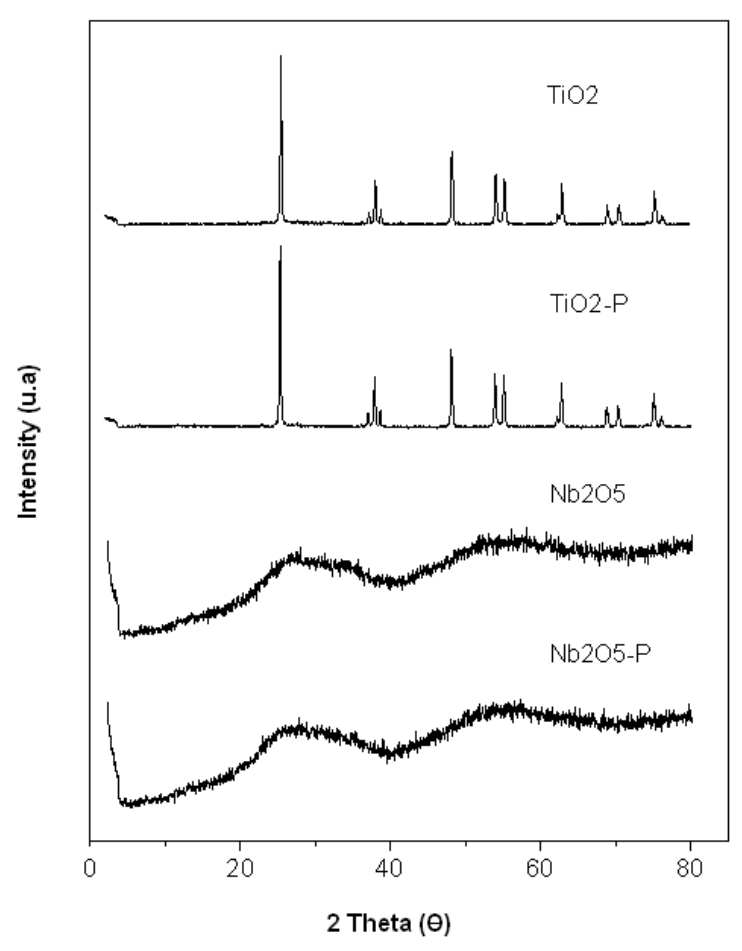

Figure 2. Catalyst X-ray diffractograms. 
Table 2. Surface basicity of the catalyst determined by $\mathrm{CO}_{2}$ TDP.

\begin{tabular}{ccc}
\hline Catalyst & $\begin{array}{c}\text { Amount of basic sites } \\
\mu \mathrm{mol} \mathrm{CO}\end{array}$ & $\begin{array}{c}\text { Density of basic sites } \\
\mu \mathrm{mol} \mathrm{CO}\end{array}$ \\
\hline $\mathrm{TiO}_{2} / \mathrm{m}^{2}$
\end{tabular}

accordance to the literature, two peaks, at $22.55^{\circ}$ and $27.65^{\circ}$, were associated to the crystalline $\mathrm{TiP}_{2} \mathrm{O}_{7}$ pattern. These peaks were observed when the phosphated $\mathrm{TiO}_{2}$ is calcinated at $1073^{\circ} \mathrm{C}$ (JCPDS, No. 38-1468). At lower calcination temperatures, such as 400 and $600^{\circ} \mathrm{C}$, there were no records of XRD peaks corresponding to titanium phosphate, suggesting that phosphorous exists as amorphous phosphate (Fan et al., 2008). In the present work, the calcination procedure was carried out at $300^{\circ} \mathrm{C}$, thus, no peaks related to phosphated titanium were expected.

\section{$3.3 \mathrm{CO}_{2}$ thermodesorption}

The $\mathrm{CO}_{2}$-TPD profiles of the calcinated catalysts are shown in Figure 3. Based on the area under each desorption profile, the total desorbed $\mathrm{CO}_{2}$ amount by mass unity and density of basic sites of each catalyst were calculated, and the results are shown in Table 2.

Comparing the niobium catalysts, the $\mathrm{Nb}_{2} \mathrm{O}_{5}$ showed a narrower peak at $642^{\circ} \mathrm{C}$. The phosphoric

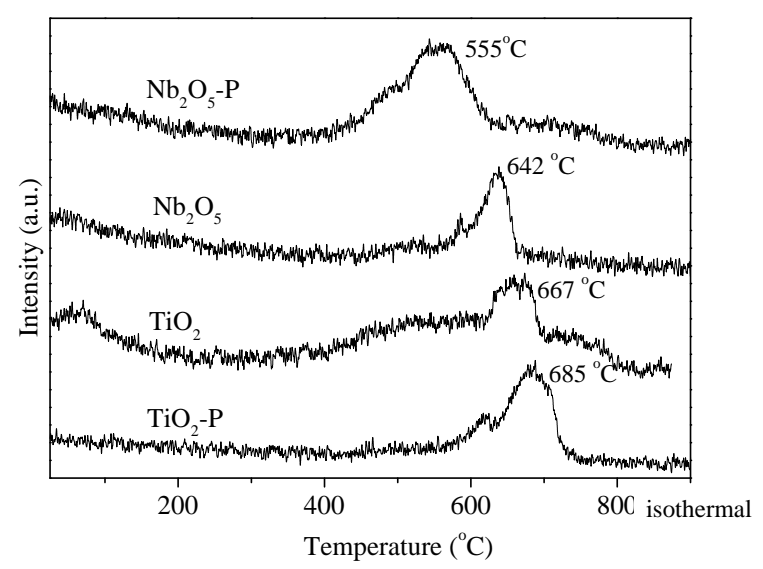

Figure 3. $\mathrm{CO}_{2}$ TDP profiles of the calcinated catalysts. acid treatment reduced the basic strength of sites, indicating a broader distribution of these sites. According to the literature, the $\mathrm{H}_{3} \mathrm{PO}_{4}$ treatment in metal oxides reduces the electron donation capacity, implying a reduction of basic strength (Samantaray and Parida, 2001). However, the titanium catalysts showed an opposite behavior. The $\mathrm{TiO}_{2}-\mathrm{P}$ showed a higher $\mathrm{CO}_{2}$ desorption temperature, suggesting that this catalyst has stronger basic sites when compared to the untreated titanium oxide.

The metal oxides basicity increase is usually related to electrons trapped in defects sites, which enhance the catalyst electron donation capacity (Samantaray and Parida, 2001). Although this phenomenon is usually observed at higher temperatures, it could be an explanation for the phosphated titanium oxide anomalous behavior.

\subsection{FTIR pyridine adsorption}

The nature and strength of acid sites were evaluated by infrared spectroscopy using pyridine as a probe molecule. The FTIR spectra are shown in Figure 4. The adsorption of pyridine on Lewis acid sites was observed in all catalysts, as evidenced by the bands at $1444 \mathrm{~cm}^{-1}, 1490 \mathrm{~cm}^{-1}$ and $1600 \mathrm{~cm}^{-1}$ (Manríquez et al., 2004). No band near $1540 \mathrm{~cm}^{-1}$, assigned to pyridine adsorbed on Brönsted sites, was clearly observed.

FTIR spectra confirmed that pyridine was not completely desorbed at $350^{\circ} \mathrm{C}$ for $\mathrm{TiO}_{2}-\mathrm{P}$ and $\mathrm{Nb}_{2} \mathrm{O}_{5}-\mathrm{P}$, which indicates the existence of stronger Lewis sites when compared to untreated catalysts. Table 3 shows the amount and density of acid sites. It also provides a classification of weak, moderate, and strong acid sites based on the fraction of sites occupied by pyridine after desorption prior to reaching $150^{\circ} \mathrm{C}$, between 150 and $250^{\circ} \mathrm{C}$, and above $350^{\circ} \mathrm{C}$, respectively. 

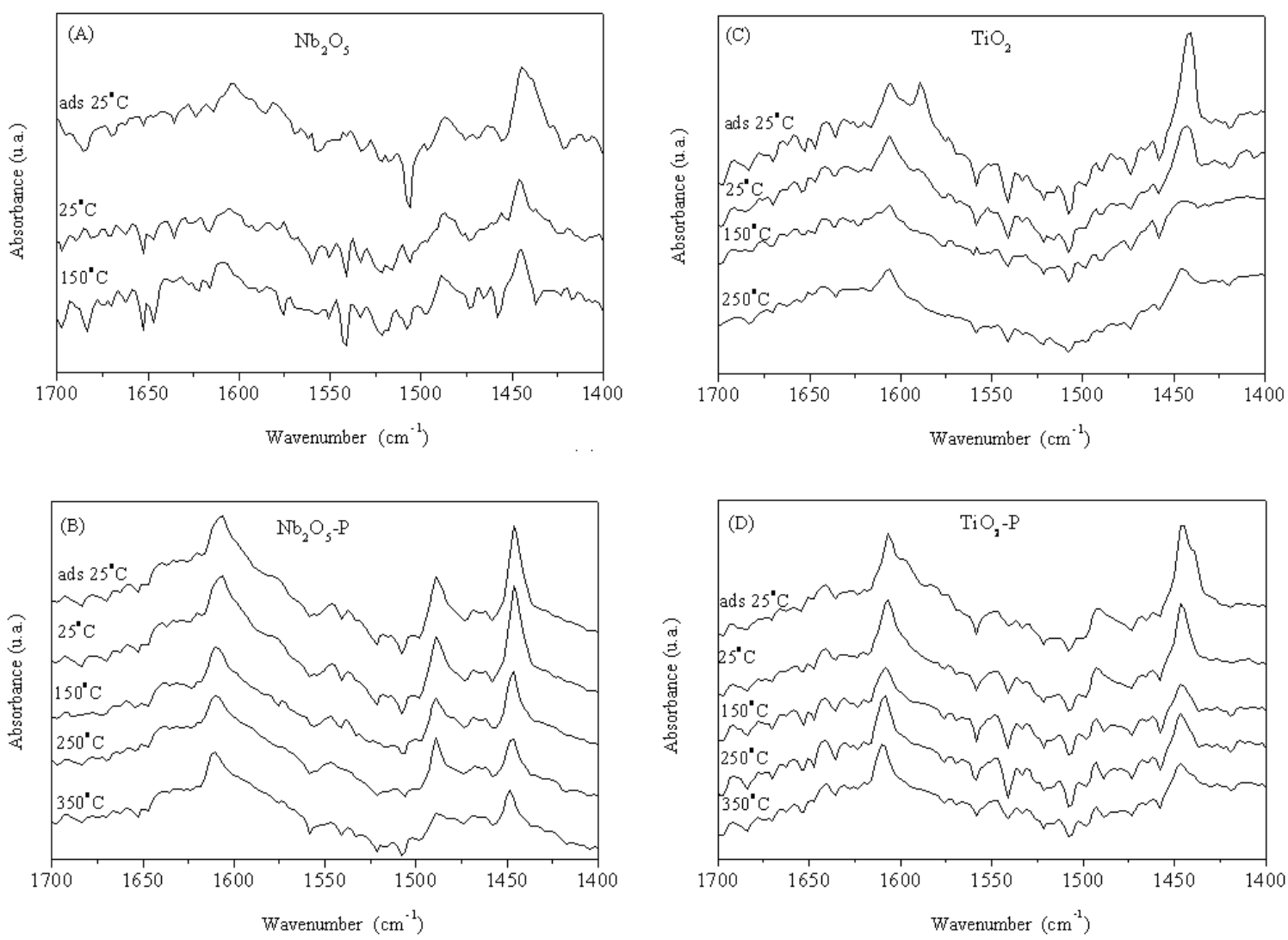

Figure 4. FTIR spectra recorded after adsorption of pyridine at room temperature and outgassing at $25^{\circ} \mathrm{C}, 150^{\circ} \mathrm{C}$, $250^{\circ} \mathrm{C}$ and $350^{\circ} \mathrm{C}$ on $\mathrm{Nb}_{2} \mathrm{O}_{5}(\mathrm{~A}), \mathrm{Nb}_{2} \mathrm{O}_{5}-\mathrm{P}(\mathrm{B}), \mathrm{TiO}_{2}(\mathrm{C})$, and $\mathrm{TiO}_{2}-\mathrm{P}(\mathrm{D})$.

The amount of acid sites of titanium catalyst had a significant increase after the $\mathrm{H}_{3} \mathrm{PO}_{4}$ treatment, while the niobium catalyst showed a reduction of sites. This reduction has already been reported by Okasaky and Kurimata (1990). According to the authors, the decrease in the amount of acid sites is attributed to the size of pyridine molecules, which are excessively large to penetrate in the micro-pores of the surface layer formed by the phosphoric acid treatment. This phenomenon was not observed in the titanium catalyst, probably due to a different surface layer structure with larger pores formed after phosphoric acid treatment.

This non-volatile layer of polyphosphate over the catalyst surface is said to be responsible for the increase of the amount of catalyst acid sites (Okazaky et al., 1987).

The increase in the amount of acid sites could not be observed after acid the treatment over niobium catalyst. Therefore, the pronounced effect on the total density of moderate and strong acid sites on this catalyst, leading to an increase from 42.5 to $60.4 \%$ after treatment, confirms the

Table 3. Acid properties of the catalysts.

\begin{tabular}{cccccc}
\hline Catalyst & $\begin{array}{c}\text { Amount of } \\
\text { acid sites } \\
\left(\mu \mathrm{mol}_{\text {pyridine }} / \mathrm{g}\right)\end{array}$ & $\begin{array}{c}\text { Density of } \\
\text { acid sites } \\
\left(\mu \mathrm{mol}_{\text {pyridine }} / \mathrm{m}^{2}\right)\end{array}$ & $\begin{array}{c}\text { Weak acid } \\
\text { sites (\%) }\end{array}$ & $\begin{array}{c}\text { Moderate acid } \\
\text { sites (\%) }\end{array}$ & $\begin{array}{c}\text { Strong acid } \\
\text { sites (\%) }\end{array}$ \\
\hline $\mathrm{TiO}_{2}$ & 16 & 2.0 & 77.0 & 23.0 & 0.0 \\
$\mathrm{TiO}_{2}-\mathrm{P}$ & 90 & 10.6 & 91.0 & 0.8 & 8.2 \\
$\mathrm{Nb}_{2} \mathrm{O}_{5}$ & 65 & 0.78 & 57.5 & 42.5 & 0.0 \\
$\mathrm{Nb}_{2} \mathrm{O}_{5}-\mathrm{P}$ & 49 & 0.67 & 39.6 & 27.0 & 33.4 \\
\hline
\end{tabular}


Table 4. Initial reaction rates of glucose, fructose, and $\mathrm{HMF}$ at $200^{\circ} \mathrm{C}$.

\begin{tabular}{cccc}
\hline Catalyst & \multicolumn{3}{c}{ Initial reaction rates $\left(\mu \mathrm{mol} \cdot \mathrm{min}^{-1} \cdot \mathrm{m}^{-2}\right)$} \\
& Glucose & Fructose & HMF \\
\hline $\mathrm{TiO}_{2}$ & 37.4 & 19.2 & 17.4 \\
$\mathrm{TiO}_{2}-\mathrm{P}$ & 46.9 & 13.1 & 18.2 \\
$\mathrm{Nb}_{2} \mathrm{O}_{5}$ & 11.7 & 2.1 & 5.3 \\
$\mathrm{Nb}_{2} \mathrm{O}_{5}-\mathrm{P}$ & 8.9 & 3.2 & 5.0 \\
\hline
\end{tabular}

effectiveness of phosphoric acid treatment in promoting the increase of catalysts acid strength. Likewise, this effect was observed by Tang et al. (2010). In this work, the authors attributed the increase of acid strength to the formation of $\mathrm{POH}$ acid site on catalyst surface, which are stronger than the $\mathrm{NbOH}$ sites.

\subsection{Glucose dehydration}

Table 4 presents the initial reaction rates of glucose consumption, fructose and HMF formation at $200^{\circ} \mathrm{C}$.

Regarding glucose consumption and HMF formation, there is a clear and direct relation between density of acid sites and initial reaction rate. However, it is relevant to note that, in the case of titanium catalysts, where the initial rates for glucose consumption and HMF formation are more important, although the phosphated catalyst showed a 5.6 times higher density of acid sites (see Table 3) as compared to the untreated titanium catalyst, the initial rates for glucose consumption and HMF formation were only 1.3 and 1.1 times higher than the untreated catalyst, respectively. These results suggest that the relationship between density of moderate/strong and weak acid sites, higher for the untreated titanium catalyst, is more appropriate for HMF formation.

As mentioned, fructose formation via glucose isomerization can be promoted either by proton transfer, by a basic-catalyzed reaction, or by hydride transfer catalyzed by Lewis acid centers. However, large amounts of catalysts with Lewis sites are required to perform glucose isomerization (Nakajima et al., 2011). Since a catalyst/glucose mass ratio of only 0.10 was used in this work, the hydride transfer mechanism was not expected to be as important as the proton transfer mechanism.

In Table 4 it can be seen that, with titanium catalysts, the initial reaction rates for fructose formation are around 5-10 times higher when compared to the niobium catalysts. However, the first ones also have a much higher density of basic sites than the latter ones (Table 2), which could explain the significant difference between initial rates.

Although the untreated titanium catalyst showed a higher initial rate for fructose formation, it had almost half of the density of basic sites observed in the $\mathrm{H}_{3} \mathrm{PO}_{4}$ treated catalyst. However, the untreated catalyst showed weaker basic sites when compared to the treated catalyst by $\mathrm{CO}_{2}-$ TPD, suggesting that weak basic sites are more important than strong basic sites for fructose formation from glucose isomerization. This assertion is in agreement with the literature (Watanabe et al., 2005B). Comparing the niobium catalysts among themselves, a slightly-higher fructose initial rate was observed with $\mathrm{Nb}_{2} \mathrm{O}_{5}-\mathrm{P}$, which also had a higher density and weaker basic sites than $\mathrm{Nb}_{2} \mathrm{O}_{5}$.

Figure 5 shows glucose conversions and HMF yields as a function of residence time for all tested catalyst at $200^{\circ} \mathrm{C}$.

HMF yields follow a bell-shaped profile, usually observed in consecutive reaction systems. Indeed, the HMF formed is subsequently decomposed into organic acids and humins, as mentioned before. For all catalytic tests, the formation of humins increased with reaction time. For longer periods of reaction the formation of this oligomeric material caused severe catalyst deactivation, covering the entire catalyst surface and granting a muddy aspect to the reaction media. Nevertheless, Figures $5 \mathrm{~A}$ and $5 B$ indicate catalytic activity for both glucose consumption and HMF decomposition at longer reaction times, probably due the organic acids formed from HMF. 

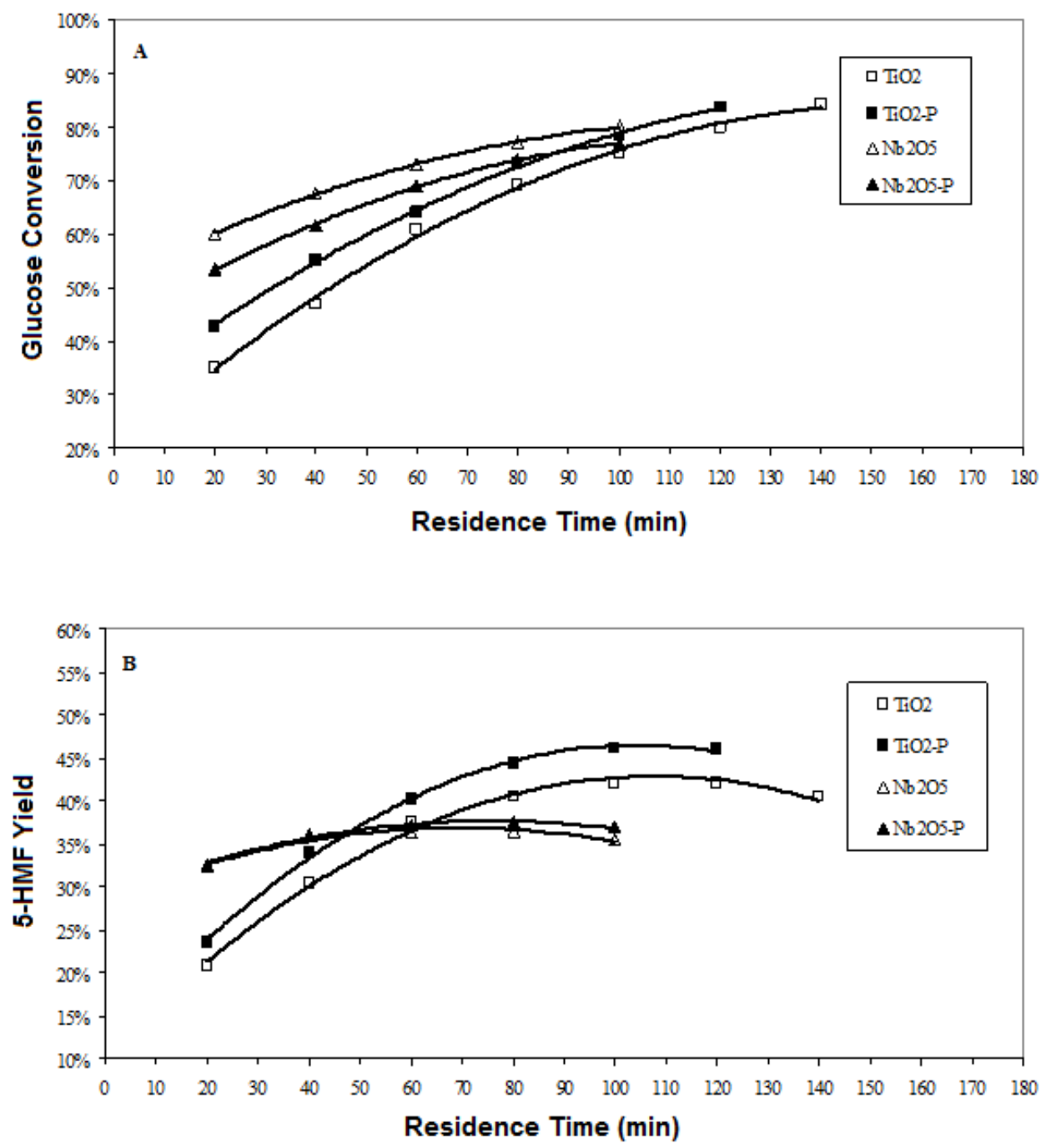

Figure 5. Glucose conversions versus time (A) and 5-HMF yields versus time (5) at $200^{\circ} \mathrm{C}$.

Trends for fructose and HMF yields and glucose conversion for each catalyst are shown in Figure 6. At lower glucose conversions (below 60\% $\mathrm{mol} / \mathrm{mol}$ ), it was observed that catalysts with weaker basic sites had higher fructose yields, corroborating to what was observed when analyzing fructose initial rates. However, most likely due to the higher amount of moderate/strong acid sites, faster glucose consumption was noticed for niobium catalyst, leading to an abrupt reduction in fructose yield.

Although the titanium catalysts had shown lower fructose yields at lower glucose conversions, the presence of considerably lower amount of moderate/strong acid sites allowed gradual fructose consumption.

At higher conversions (above $70 \% \mathrm{~mol} / \mathrm{mol}$ ), a process condition where the deactivation by humins formation is more severe, the niobium catalysts showed lower HMF yields than the titanium catalysts.

These results could be associated with the higher fructose availability at higher glucose conversion for titanium catalysts, and with the considerably higher amount of moderate/strong acid sites presented in the reaction medium when niobium catalysts were used. Although these strong acid sites promote glucose and fructose consumption and the HMF formation, they also promote the decomposition of HMF in organic acids and humins.

Among all catalysts, the $\mathrm{H}_{3} \mathrm{PO}_{4}$ treated titanium catalyst achieved the highest $\mathrm{HMF}$ at high glucose conversions. High densities of basic sites generated after acid treatment associated to its low acid strength probably allowed this solid to keep its 


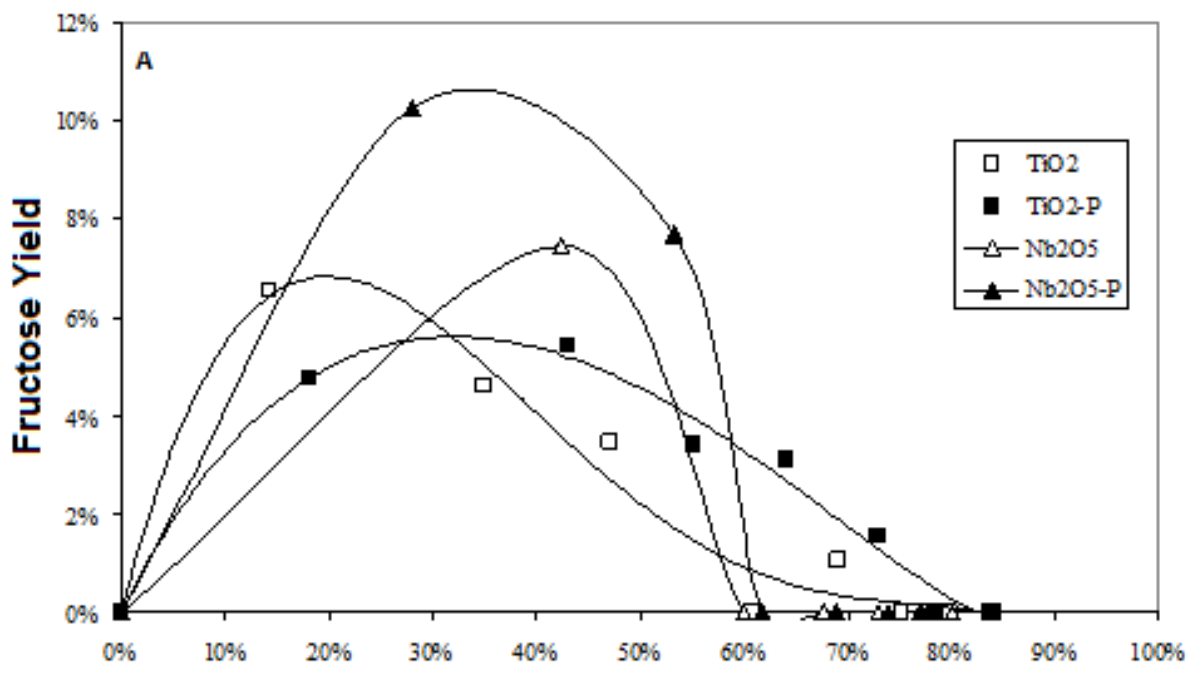

Glucose Conversion

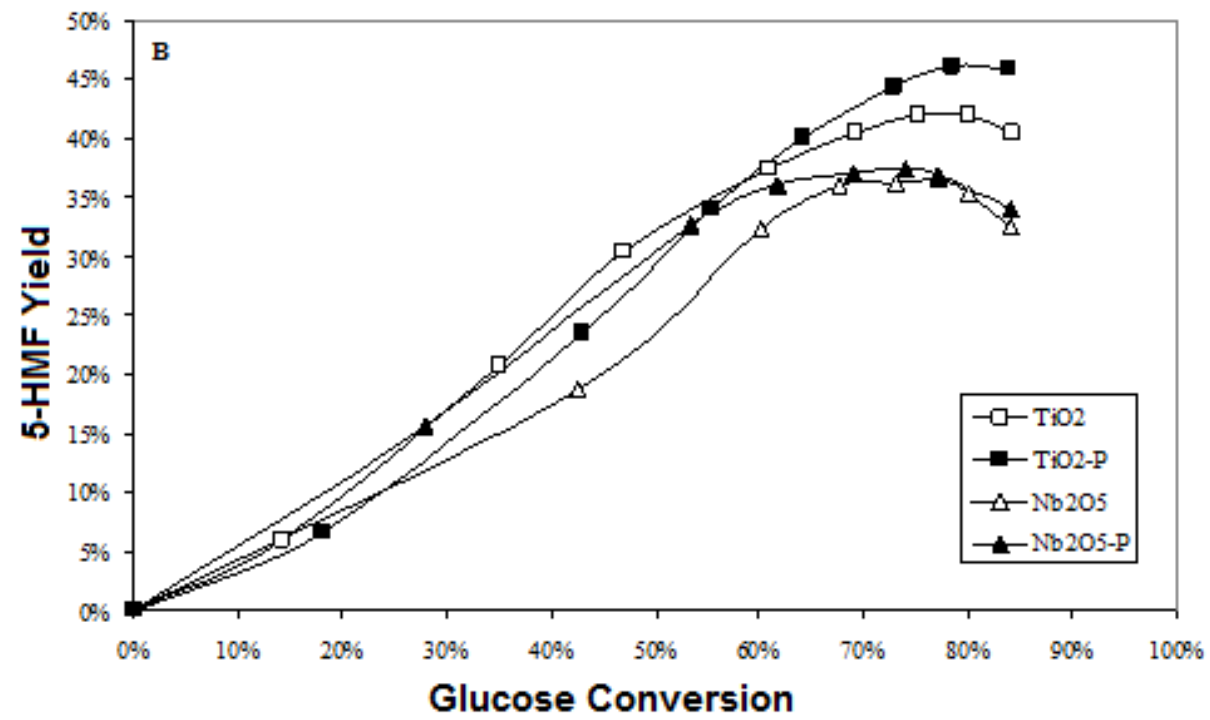

Figure 6. Fructose yield versus glucose conversion (A) and HMF yield versus glucose conversion (B) at $200^{\circ} \mathrm{C}$.

activity for longer periods and to be more selective than the other catalysts. This result could be even more pronounced if its basic sites strength could be reduced with the phosphation processes.

\section{CONCLUSIONS}

The effects of $\mathrm{H}_{3} \mathrm{PO}_{4}$ treatment on the catalytic activity of niobium and titanium oxides were evaluated on glucose dehydration in aqueous medium. The activities under study were related to catalyst acid and basic properties. The experiments confirmed that weak basic sites favor glucose isomerization into fructose while catalysts with moderate and strong acid sites favor not only the formation of HMF and glucose conversion, but also HMF decomposition in organic acids and humins. Therefore, in order to increase the HMF yield, a compromise between moderate acidity, weak basicity and high basic and acid sites densities must be achieved.

Thus, phosphated $\mathrm{TiO}_{2}$ stands out as a more promising catalyst for glucose dehydration. However, the severe deactivation process observed for all catalysts indicates that stability and regeneration tests must be carried out to develop guidelines for the continuous process for synthesis of HMF from glucose in aqueous medium. 


\section{ACKNOWLEDGMENTS}

The authors acknowledge Instituto Nacional de Tecnologia and LabTecH/EQ/UFRJ for the characterization analyses.

\section{REFERENCES}

Armaroli, T.; Busca, G.; Carlini, C.; Giuttari, M.; Galleti, A.; Sbrana, G. Acid sites characterization of niobium phosphate catalysts and their activity in fructose dehydration to 5-hydroxymethyl-2furaldehyde. Journal of Molecular Catalysis A: Chemical, v.151, p.233-243, 2000. http://dx.doi.org/10.1016/S1381-1169(99)00248-4

Cartini, P.; Gervasini, A.; Biella, S.; Auroux, A. Niobic acid and niobium phosphate as highly acidic viable catalysts in aqueous medium: fructose dehydration reaction. Catalysis Today, v. 118, p. 373-378, 2006.

http://dx.doi.org/10.1016/i.cattod.2006.07.024

Cartini, P.; Gervasini, A.; Marzo, M. Absence of expected side-reactions in the dehydration reaction of fructose to HMF in water over niobic acid catalyst. Catalysis Communications, v.12, p.1122-1126, 2011.

http://dx.doi.org/10.1016/i.catcom.2011.03.025

Corma, A.; Iborra, S.; Velty, A. Chemical routes for the transformation of biomass into chemicals. Chemical Reviews, v. 107, p.2411-2502, 2007. http://dx.doi.org/10.1021/cr050989d

Emeis; C. A. Determination of integrated molar extinction coefficients for infrared absorption bands of pyridine adsorbed on solid acid catalysts. Journal of Catalysts, v. 141, p.347-354, 1993. http://dx.doi.org/10.1006/icat.1993.1145

Fan, C.; Guan, H.; Zhang, H.; Wang, J.; Wang, S.; Wang, $X$. Conversion of fructose and glucose into 5hydroxymethylfurfural catalyzed by a solid heteropolyacid salt. Biomass and Bioenergy, v.35, p.2659-2665, 2011.

http://dx.doi.org/10.1016/i.biombioe.2011.03.004

Fan, X.; Yua, T.;Wang, Y.; Zheng, J.; Gao, L.; Li, Z.; Ye, J.; Zou, Z.. Role of phosphorus in synthesis of phosphated mesoporous $\mathrm{TiO}_{2}$ photocatalytic materials by EISA method, Applied Surface Science, v. 254, p.5191-5198, 2008.

http://dx.doi.org/10.1016/j.apsusc.2008.02.038
Gruter, G.J.M. Hydroxymethylfurfural ethers from sugars and olefins, US2010/0299991A1, 2010A.

Gruter, G.J.M. Hydroxymethylfurfural ethers from sugars or $\mathrm{HMF}$ and branched alcohols, US2010/0218416A1, 2010B.

Gruter, G.J.M.; Manzer, L.E.; Hydroxymethylfurfural ethers from sugars and higher alcohols, US2010/0218415A1, 2010A.

Gruter, G.J.M.; Manzer, L.E. Hydroxymethylfurfural ethers from sugars or HMF and mixed alcohols, US2010/0058650A1, 2010B.

Lansalot-Matras; C.; Moreau; C. Dehydration of fructose into 5-hydroxymethylfurfural in the presence of ionic liquids. Catalysis Communications, v.4; p.517-520, 2003.

http://dx.doi.org/10.1016/S1566-7367(03)00133-X

Lanzafame, P.; Temia, D.M.; Perathonera, S.; Centia, G.; Macario, A.; Aloise, A.; Giordano, G. Etherification of 5-hydroxymethyl-2-furfural (HMF) with ethanol to biodiesel components using mesoporous solid acidic catalysts. Catalysis Today, v. 175, p.435-441, 2011.

http://dx.doi.org/10.1016/j.cattod.2011.05.008

Leshkov; Y.R.; Chheda; J.N.; Dumesic; J.A. Phase modifiers promote efficient production of hydroxymethylfurfural from fructose. Science, v.312; p.1933- 1937, 2006.

http://dx.doi.org/10.1126/science.1126337

Lewkowski, J. Synthesis, chemistry and applications of 5-hydroxymethylfurfural and its derivatives, ARKIVOC, (i) p.17-54, 2001.

Manríquez, M.E.; López, T.; Gómeza, R.; Navarrete, J.. Preparation of $\mathrm{TiO}_{2}-\mathrm{ZrO}_{2}$ mixed oxides with controlled acid-basic properties. Journal of Molecular Catalysis A: Chemical, v. 220, p.229-237, 2004.

http://dx.doi.org/10.1016/i.molcata.2004.06.003

Nakajina, K.; Baba, Y.; Norma, R.; Kitano, M.; Kondo, J.N.; Hayashi, S.; Hara, M. $\mathrm{Nb}_{2} \mathrm{O}_{5} \cdot \mathrm{nH}_{2} \mathrm{O}$ as a heterogeneous catalyst with water-tolerance Lewis acid sites. Journal of American Chemical Society, v. 133, p.4224-4227, 2011.

http://dx.doi.org/10.1021/ja110482r 
Okazaki, S.; Kurimata, M.; lizuka, T.; Tanabe, K. The Effect of Phosphoric Acid Treatment on the Catalytic Property of Niobic Acid. Bulletin of the Chemical Society of Japan, v. 60, p.37-41, 1987. http://dx.doi.org/10.1246/bcsj.60.37

Okazaki, S.; Kurosaki, A. Acidic Properties and Catalytic Activities of Niobic Acid Treated With Phosphoric Acid. Catalysis Today, v. 8, p.113-122, 1990. http://dx.doi.org/10.1016/0920-5861(90)87012-R

Okuhara, T. Water-tolerant solid acid catalysts. Chemical Reviews, v. 102, p.3641-3666, 2002. http://dx.doi.org/10.1021/cr0103569

Petersen, G.; Werpy, T.; Top value added chemicals from biomass volume I - results of screening for potential candidates from sugars and synthesis gas, US Department of Energy, 2004.

Samantaray, S.K.; Parida, K. Studies on anionpromoted titania 3 . Effect of concentration and source of phosphate ion, method of preparation, and activation temperature on redox, acid-base, textural and catalytic properties of titania. Journal of Molecular Catalysis A: Chemical, v.176, p.151163, 2001.

http://dx.doi.org/10.1016/S1381-1169(01)00247-3

Souza, R.L., Yu, H., Rataboul, F., Essayem, N. 5Hydroxymethylfurfural (HMF) Production from Hexoses: Limits of Heterogeneous Catalysis in Hydrothermal Conditions and Potential of Concentrated Aqueous Organic Acids as Reactive Solvent System Challenges, v.3, p. 212-232, 2012.
Tang, Z-C; Yu, D-H; Li, H; Huang, H. Phosphoric Acid Modified $\mathrm{Nb}_{2} \mathrm{O}_{5}$ : A Selective and Reusable Catalyst for Dehydration of Sorbitol to Isosorbide. Bulletin of the Korean Chemical Society, v.31, 12, p. 3679-.3683 2010.

Tong, X.; Ma, Y.; Li, Y. Biomass into chemicals: Conversion of sugars to furan derivatives by catalytic processes. Applied Catalysis A: General, v.385; p.1-13, 2010.

http://dx.doi.org/10.1016/i.apcata.2010.06.049

Watanabe, M.; Aizawa, Y.; lida, T.; Aida, T.;Levy, C.; Sue, K.; Inomata, H. Catalytic glucose and fructose conversions with $\mathrm{TiO}_{2}$ and $\mathrm{ZrO}_{2}$ in water at $473 \mathrm{~K}$ : Relationship between reactivity and acidbase property determined by TPD measurement. Carbohydrate Research, v. 340, p.1925-1930, 2005A. http://dx.doi.org/10.1016/i.carres.2005.06.017

Watanabe, M.; Aizawa, Y.; lida, T.; Nishimura, R.; Inomata, H. Glucose reactions with acid and base catalysts in hot compressed water at $473 \mathrm{~K}$. Applied Catalysis A: General, v. 295, p.150-156, 2005B. http://dx.doi.org/10.1016/i.apcata.2005.08.007

Yang, F.; Liu, Q.; Bai, X.; Du; Y. Conversion of biomass into 5-hydroxymethylfurfural using solid acid catalyst. Bioresource Technology, v.102, p.3424-3429, 2011.

http://dx.doi.org/10.1016/i.biortech.2010.10.023 